\title{
Economic status and acknowledgement of earned entitlement
}

\author{
Abigail Barr ${ }^{*}$, Justine Burns $^{\dagger}$, Luis Miller ${ }^{\ddagger}$, and Ingrid Shaw ${ }^{\S}$
}

13 February 2015

\begin{abstract}
We present a series of experiments that investigates whether tendencies to acknowledge entitlement owing to effort and productivity are associated with withinsociety economic status. Each participant played a four-person dictator game under one of two treatments, under one initial endowments were earned, under the other they were randomly assigned. The experiments were conducted in the United Kingdom, and South Africa. In both locations we found that relatively well-off individuals make allocations to others that reflect those others' initial endowments more when those endowments were earned rather than random; among relatively poor individuals this was not the case.
\end{abstract}

Keywords: Distributive Justice, Inequality, Laboratory Experiments.

JEL classification: D63, C91, C93.

\footnotetext{
* University of Nottingham, School of Economics, Room B44 Sir Clive Granger Building University Park Nottingham NG7 2RD UK. Abigail.Barr@nottingham.ac.uk.

${ }^{+}$University of Cape Town, School of Economics, 5.03, New Building, Middle Campus, Cape Town, SA. Justine.Burns@uct.ac.za.

${ }_{\ddagger}$ University of the Basque Country (UPV/EHU), School of Economics and Business, Av. Lehendakari Aguirre 83, 48015 Bilbao, Spain. luismiguel.miller@ehu.es. Corresponding author.

ingridlshaw@gmail.com.
} 


\section{Economic status and the acknowledgement of earned entitlement}

\section{INTRODUCTION}

The notion of distributive justice underpinning market-driven societies is that effort and productivity, owing to inherent talent or acquired ability, should be acknowledged and rewarded (Miller 1976, Milne 1986). In behavioural experiments, university students in the US and Europe have repeatedly acted in accordance with this notion. ${ }^{1}$ However, Jakiela (2011) found that, in dictator games played with either windfalls or earnings, while US students exhibited a strong earned endowment effect, i.e., they were significantly more inclined to redistribute windfalls than earnings, poor Kenyan villagers did not. And Cappelen et al (2013) found that, in dictator games played with earnings that depended on a mix of productivity and luck, students in Tanzania and Uganda rewarded productivity significantly less than students in Germany and Norway. Each of these three studies presents evidence of an Africa effect that is consistent with an argument put forward by Platteau (2000), that owing to Africa's tribal structure and dependence on agriculture egalitarianism prevails and effort and productivity tend not to be rewarded. Such an Africa effect could, as Platteau points out, explain Africa's slow economic development.

To our knowledge, Jakiela (2011) and Cappelen et al (2013) are the only studies that identify systematic differences in notions of distributive justice across societies using behavioural experimental methods. However, numerous analyses of attitudinal surveys such as the World Values Survey, the US General Social Survey and the European Social Survey indicate that, within developed market-driven societies, the poor favour redistribution while the rich do not

\footnotetext{
' Contributions to this literature include Hoffman et al (1994), Ruffle (1998), Konow (2000), Rutstrom and Williams (2000), Cherry (2001), Gantner et al, (2001), Cherry et al (2002), Frohlich et al (2004), Cappelen et al (2007), Oxoby and Spraggon (2008), List and Cherry (2008).
} 
(Alesina and Giuliano 2011). This difference is consistent with early theoretical models of the political economy, which assume that people care only about their own consumption. ${ }^{2}$ However, it is also consistent with models incorporating an other-regarding preference for fairness and Babcock and Lowenstein's (1997) proposition that "people tend to arrive at judgments of what is fair or right that are biased in the direction of their own self-interests" (Babcock and Loewenstein, 1997: 111).

In Kenya using a behavioural experiment similar to Jakiela's (2011) conducted within the context of a field experiment, Jakiela et al (2014) identified a causal effect running from academic achievement to acknowledgment of earned entitlement. If we assume that higher academic achievement is associated with higher expected future earnings, this finding is consistent with Babcock and Lowenstein's (1997) proposition.

The objective of this paper is to take a first step towards reconciling these distinct strands in the literature, i.e.: the experimental studies focusing on US and European students who have repeatedly acknowledged earned entitlement; the studies of Jakiela (2011) and Cappelen et al (2013) identifying Africa-based subject pools that are less or entirely disinclined to acknowledge earned entitlement; the survey-based analyses of Alesina and Giuliano (2011) and others, indicating that people at the lower end of the income distributions of developed countries might also be less or entirely disinclined to acknowledge earned entitlement; and the recent study by Jakiela et al (2014) revealing a causal effect that is consistent with Babcock and Lowestein (1997) within an African country.

The most notable lacuna in the body of evidence just described is experimental data pertaining to the notions of distributive justice held by poorer people in developed countries. Such data would allow us to establish whether the observed differences in attitudes towards redistribution

\footnotetext{
${ }^{2}$ See Persson and Tabellini (2002) and Drazen (2002) for reviews of this literature.
} 
between the rich and poor in developed countries derive from nothing more than a preference for own consumption or from other regarding preferences that depend on their relative economic status. In addition, if, in accordance with Babcock and Lowenstein (1997), we find that poor people in developed countries do not acknowledge earned entitlement, the prior discovery of people in Africa who do not acknowledge earned entitlement must be reviewed in a different light.

To address this lacuna we conducted a series of experiments designed to investigate whether an individual's tendency to acknowledge earned entitlement is associated with his or her economic status relative to others in the UK. We selected unemployed residents of Oxford to represent low economic status individuals and students and employed individuals also residing in Oxford as bases for comparison. The students allowed us to demonstrate that, when applied to the standard participant pool, our experiment yields the usual result, i.e., an earned endowment effect (EEE hereafter). However, the employed are the better basis for comparison as they, rather than investing in their future economic status, are realizing their current actual economic status and are likely to be more comparable to the unemployed in terms of age, marital status and familial responsibilities. We found a statistically significant EEE among the students and employed and no EEE among the unemployed.

Then, to investigate the generalizability of our findings, we extended the series to South Africa. We chose South Africa because, while it is a middle income country, it is African, it has many problems in common with its lower income neighbours and, especially important given our objective, it has one of the highest inequality rates in the world (Arden 2014). In South Africa, we focused on Cape Town, the location of one of the continent's best universities. Thus, we were able to build a participant sample that was highly comparable to the Oxford sample in many regards, while varying in terms of its wider societal context. In Cape Town, as in Oxford, we found a statistically significant EEE among the employed and no EEE among the 
unemployed. However, the average South African university student, like the Tanzanian and Ugandan students in Cappelen et al's (2013) study, tended not to acknowledge earned entitlement. Anticipating this and a less clear-cut distinction between the employed and unemployed, in South Africa our research design included the collection of data on participants' perceptions of their households' economics status. When we used this data to re-categorize the Cape Town participants into the relatively well-off and the relatively poor, we found a highly statistically significant EEE among the relatively well-off, but not among the poor. ${ }^{3}$

Our findings support Babcock and Lowenstein's (1997) proposition and indicate that it may explain variations in notions of distributive justice not only within rich countries like the UK but also in middle income countries with high inequality like South Africa. At the same time, our findings are consistent with those of Cappelen et al (2013) and suggest that, while Jakiela and co-authors' findings are consistent with Platteau's (2000) argument, they might alternatively be owing to the low economic status of their Kenyan farmers relative to other Kenyans.

The remainder of the paper is organized as follows: section 2, directly below, presents our experimental design, analytical framework and hypotheses; section 3 presents the results; and section 4 concludes.

\section{EMPIRICAL STRATEGY}

\subsection{Experimental Design}

At the core of the experimental design is a four person dictator game (4PDG). In this game, each participant $i$ is initially endowed with a positive sum of money, $y_{i}$, the initial endowments vary

\footnotetext{
${ }^{3}$ After conducting a similar but not identical re-categorization of the Oxford participants, we could not reject the hypothesis that the two datasets could be pooled in a single regression analysis. The results of this exercise are reported in the on-line Supplementary Information (SI).
} 
across the four participants, each knows his or her own initial endowment and the initial endowments of the three other participants, and each is free to make final allocations to him or herself and to the others subject to the constraint that the sum of the four allocations must equal the sum of the four initial endowments. Once all the participants have made their allocation decisions, the decisions of one are randomly selected to determine the final payoffs of all four participants. Play is one shot and anonymous, i.e., the participants never know the precise identities or full allocation sets of their three co-participants.

Prior to the 4PDG, the participants engaged in a real effort task and, in more than half of the experimental sessions, their performance ranking in that task determined their initial endowments. However, in order to control for the possible conditioning of final allocations on initial endowments even when they are not earned, in some experimental sessions the participants' initial endowments were randomly assigned. These participants were also engaged in the real effort task, but their performance in that task did not determine their initial endowment in the 4PDG. Below, we use the term "earned treatment" when referring to the sessions in which the participants' performance in the real effort task determined their initial endowments and "random treatment" when referring to the sessions in which the participants' initial endowments were randomly assigned.

The distribution of initial endowments across participants within sessions did not vary depending on the treatment (earned or random). In a session involving 16 Oxford-based participants (so four game sets of four participants), two received initial endowments of $£ 20$, four initial endowments of $£ 14$, two initial endowments of $£ 12$, two initial endowments of $£ 10$, four initial endowments of $£ 8$, and two initial endowments of $£ 2 .{ }^{4}$ This enabled us to arrange the

\footnotetext{
${ }^{4}$ In relative terms, the distribution of initial endowments in Cape Town was identical. We applied a conversion rate of $£ 1$ to 7 Rand to the initial endowments. At the time of the Oxford experiments, $£ 1$ was worth 1.64 USD and, at the time of the Cape Town experiments, 7 Rand was worth 1.03USD.
} 
16 participants into four game sets, with each set’s initial endowments summing to $£ 44 .^{5}$ In sessions where initial 4PDG endowments were earned, all 16 participants were ranked according to performance in the real effort task, their initial endowments were then assigned accordingly and then they were assigned to game sets. Basing initial endowments on performance rank rather than directly on performance ensured the distribution of initial endowments was balanced across treatments and participant types. ${ }^{6}$ In sessions where initial 4PDG endowments were random, all 16 participants were simultaneously and randomly assigned their initial endowments and to their game sets.

\subsection{Analytical Framework}

Several notions of distributive justice may guide participants' decisions in the 4PDG. To characterize these notions, we rely on the classification proposed by Cappelen et al. (2007). A participant applying a strict egalitarian ideal would equalize final payoffs in the 4PDG, regardless of the treatment. A strict libertarian would leave initial endowments untouched in both, the random and the earned treatment. However, a meritocratic or liberal egalitarian participant would acknowledge initial endowments only in the earned treatment. Of course, we also expect to find purely selfish participants, who take everything for themselves, and intermediate types, whose behavior reflects a mix of two or more ideals as well as some selfishness. To include intermediate types in the analysis, we use an ad hoc variant of Cappelen et al's (2007) utility function to develop our analytical framework. ${ }^{7}$

Consider a participant $i$ with the following utility function:

$$
V_{i}=x_{i i}-\beta_{i} \sum_{j \neq i}\left(x_{i j}-m_{i j}^{k}\right)^{2}
$$

\footnotetext{
${ }^{5}$ In two of the four game sets initial endowments were highly unequal (£20, £14, £8, £2). In two they were relatively equal $(£ 14, £ 12, £ 10, £ 8)$.

${ }^{6}$ See the on-line Supplementary Information for descriptive statistics and a full analysis.

${ }^{7}$ Our utility function differs from Cappelen et al's (2007) in three ways: we focus on proportional allocations and initial endowments because, in our game, the sums of the initial endowments and the final allocations are fixed; we condition on context because we conducted both earned and random initial endowment versions of the game; and we normalize so that the parameter on own final allocation is 1 .
} 
where $x_{i i}$ is participant $i$ 's allocation to him or herself in the 4PDG expressed as a proportion of the maximum amount that $i$ could allocate to him or herself (£44), $x_{i j}$ is participant $i$ 's allocation to participant $j$ also expressed as a proportion of the maximum amount that $i$ could allocate to $j$ (also $£ 44$ ), $m_{i j}^{k}$ is the proportional allocation to $j$ that participant $i$ perceives as fair in context $k$, and $\beta_{i}$ is the preference parameter associated with adherence to own notions of distributive justice. Assuming an interior solution, maximizing $V_{i}$ subject to the constraint $\sum_{j=1}^{4} x_{i j}=1$ yields the optimal allocations, $x_{i i}^{*}$ and $x_{i j \neq i}^{*}$ :

$$
x_{i i}^{*}=m_{i i}^{k}+\frac{3}{2 \beta_{i}} \quad x_{i j \neq i}^{*}=m_{i j}^{k}-\frac{1}{2 \beta_{i}}
$$

Thus, $i$ 's optimal allocations are directly related to the allocations that $i$ perceives as fair and, as long as $0<\beta_{i}<\infty$, the allocation to self is greater than the fair allocation to self and the allocation to each of the others is less than the fair allocation to each of those others.

The two most likely determining factors of $m_{i j}^{k}$ are participant $j$ 's initial endowment expressed as a proportion of the sum of all initial endowments, $y_{j}$, and the equal division, $\bar{y}(=1 / 4)$, and given the model thus far, it is natural to express $m_{i j}^{k}$ as the weighted average of these two, $m_{i j}^{k}=\alpha_{i}^{k} y_{j}+\left(1-\alpha_{i}^{k}\right) \bar{y}$

Two decision-making contexts were created, in one the initial endowments, $y_{j}$, were earned (indicated below by $k=e$ ), in the other they were random (indicated below by $k=r$ ). The weights assigned by different types of $i$ to their co-participants' initial endowments in these two contexts depend on the extent to which they acknowledge effort and productivity. If individuals prefer not to take from others, both $\alpha_{i}^{e}$ and $\alpha_{i}^{r}$ are greater than zero. ${ }^{8}$ Then, for individuals who do not acknowledge effort and productivity $\alpha_{i}^{e}$ equals $\alpha_{i}^{r}$ and so their allocations to themselves

\footnotetext{
${ }^{8}$ Bardsley (2008) and List (2007) show that final allocations in a two-person dictator game depend on the initial endowment distribution in a manner that is consistent with a preference not to take. Krupka and Weber (2008) show that a given final allocation is less socially acceptable if it is achieved by taking rather than giving.
} 
and others are identically related to initial endowments in each of the contexts. In contrast, for individuals who do acknowledge effort and productivity $\alpha_{i}^{e}$ will be greater than $\alpha_{i}^{r}$, and their allocations to themselves and others will be more strongly related to initial endowments in the earned treatment as compared to the random treatment.

We can investigate whether any given type of experimental participant is subject to an EEE by estimating linear regression Model 1:

$$
x_{i j \neq i}^{*}=a_{0}+a_{1} E_{i}+a_{2} y_{j}+a_{3}\left(E_{i} * y_{j}\right)+\varepsilon_{i j}
$$

where $E_{i}$ takes the value 1 if $i$ played under the earned treatment and zero if $i$ played under the random treatment, $a_{0}, a_{1}, a_{2}$, and $a_{3}$ are the coefficients to be estimated, and $\varepsilon_{i j}$ is the error term which is non-independent within $i$ and will be adjusted accordingly by clustering. ${ }^{9}$

If there are libertarian types in the sample, the average amount allocated to $j$ will be increasing in $j$ 's initial endowment in the random treatment and the coefficient $a_{2}$ will be positive. The more the sample tends towards liberal egalitarianism, the larger the coefficient $a_{3}$. All other things being equal, an EEE manifests in two ways: a negative $a_{1}$ and a positive $a_{3}$. Graphically, the EEE constitutes an anti-clockwise rotation in the relationship between $j$ 's initial endowment and $i$ 's final allocation to $j$ as we move from the random to the earned treatment.

Initially, we estimate this model for each of our Oxford and Cape Town participant sub-samples in turn. Below, we refer to these models as Model 1s, based only on the student sample in a particular location, Model 1e, based only on the employed sample in a particular location, and Model $1 \mathrm{u}$, based only on the unemployed sample in a particular location. Then we pool across pairs of sub-samples and introduce one sub-sample identifier and three more interaction terms.

\footnotetext{
${ }^{9}$ The validity of this approach depends on the assumption that $\beta_{i}$ and the $m_{i j}$ are independent. If this is not the case $\varepsilon_{i j}$ may be correlated with $y_{j}, E$ and $y_{j} \times E$, leading to endogeneity bias. We address this issue in footnote 12 .
} 
So, when comparing the unemployed to the employed in Oxford, for example, we pool the two sub-samples and estimate Model 2:

$$
\begin{aligned}
x_{i j \neq i}^{*}=a_{0}+a_{1} E_{i}+a_{2} y_{j}+ & a_{3}\left(E_{i} * y_{j}\right)+ \\
& +a_{4} U_{i}+a_{5}\left(E_{i} * U_{i}\right)+a_{6}\left(y_{j} * U_{i}\right)+a_{7}\left(E_{i} * y_{j} * U_{i}\right)+\varepsilon_{i j}
\end{aligned}
$$

where $U_{i}$ equals 1 if the decision-making participant $i$ is unemployed and zero if $i$ is employed.

Now, the coefficients $a_{0}, a_{1}, a_{2}$, and $a_{3}$ pertain to the employed participants and the coefficients $a_{4}, a_{5}, a_{6}$, and $a_{7}$ identify any differences between the unemployed and the employed. Most importantly, $a_{5}$ and $a_{7}$ identify differences in the EEE. ${ }^{10}$

With these models fully specified, we can set out our hypotheses in precise terms.

Hypothesis 1: For high economic status individuals, i.e., students and employed people, the EEE is positive, so the coefficient $a_{3}$ in Models $1 \mathrm{~s}, 1 \mathrm{e}$ and 2 is positive and the coefficient $a_{1}$ in Models 1s, 1e and 2 is negative.

Hypothesis 2: For low economic status individuals, i.e., unemployed people, the EEE is zero, so the coefficients $a_{1}$ and $a_{3}$ in Model 1e are zero; the coefficients $a_{5}$ and $a_{7}$ in Model 2 are positive and negative respectively; and the sum of coefficients $a_{1}$ and $a_{5}$ and the sum of coefficients $a_{3}$ and $a_{7}$ in Model 2 are zero.

\section{RESULTS}

\subsection{Oxford, UK}

We ran 15 experimental sessions in Oxford. All the sessions were conducted at the laboratory of the Nuffield Centre for Experimental Social Sciences.

\footnotetext{
${ }^{10}$ In all estimations we exclude those participants who made the maximal allocation to themselves. Only 23 (5\%) subjects behaved in this way.
} 
Table 1

Participants and treatment assignment in the UK

\begin{tabular}{lcccc}
\hline & \multicolumn{4}{c}{ Participant sample } \\
\cline { 2 - 5 } & All & Student & Employed & Unemployed \\
\hline Sample sizes & 204 & 80 & 62 & 62 \\
\hline Characteristics & & & & \\
$\quad$ Female (\%) & $46 \%$ & $48 \%$ & $61 \%$ & $27 \%$ \\
$\quad$ Age & 32.1 & 22.4 & 37.7 & 39.0 \\
$\quad$ Years in education & 12.8 & 12.7 & 14.0 & 12.0 \\
\hline Treatments & & & & \\
$\quad$ Random (\%) & $46 \%$ & $44 \%$ & $47 \%$ & $46 \%$ \\
$\quad$ Earned (\%) & $54 \%$ & $56 \%$ & $53 \%$ & $54 \%$ \\
\hline
\end{tabular}

The Oxford sample contained 204 participants; 80 students (61 in universities, 19 in a local College of Further Education), 62 unemployed, and 62 employed. The main characteristics of this sample and their assignment to treatments are presented in Table 1.

Before turning to the regression analyses and the formal tests of the hypotheses stated above, it is useful to take a look at the experimental data. In Table 2, we present a brief summary of behaviour for the sub-samples of participants that played under the random and earned treatments. In the first column, we pool across participant types. In the second, third, and fourth columns we present the same statistics for students, the employed, and the unemployed participants separately. Table 2 reveals that only 12 and 5 percent of the participants in the random and earned treatments respectively acted in accordance with pure selfishness by allocating all the money to themselves. These proportions are low compared to other studies. This may be owing to the experiment not being computerized or the nature of the real effort task. Given our objectives, this feature of the data is useful. The table also reveals that 38 and 29 percent of the participants made equal allocations to themselves and others under the random and earned treatments respectively and that, while only 1 percent left the initial endowments untouched in the random treatment, 13 percent did so in the earned treatment. 
Table 2

UK experimental data summarized

\begin{tabular}{lcccc}
\hline & \multicolumn{3}{c}{ Participant sample } \\
\cline { 2 - 4 } & All & Student & Employed & Unemployed \\
\hline Random treatment & & & & \\
\hline Allocated zero to all others (\%) & $11.8 \%$ & $8.1 \%$ & $18.5 \%$ & $10.3 \%$ \\
Allocated 1/4 to each (\%) & $37.6 \%$ & $27.0 \%$ & $55.6 \%$ & $34.5 \%$ \\
Left initial endowments unchanged (\%) & $1.1 \%$ & $0.0 \%$ & $3.7 \%$ & $0.0 \%$ \\
Allocation to self (mean proportion) & 0.43 & 0.44 & 0.43 & 0.42 \\
Allocation to others (mean proportion) & 0.19 & 0.19 & 0.19 & 0.19 \\
\hline Earned treatment & & & & \\
\hline Allocated zero to all others (\%) & & & & $3.0 \%$ \\
Allocated $1 / 4$ to each (\%) & $5.4 \%$ & $9.3 \%$ & $2.9 \%$ & $36.4 \%$ \\
Left initial endowments unchanged (\%) & $28.8 \%$ & $23.3 \%$ & $28.6 \%$ & $9.1 \%$ \\
Allocation to self (mean proportion) & $12.6 \%$ & $11.6 \%$ & $17.1 \%$ & 0.35 \\
Allocation to others (mean proportion) & 0.37 & 0.42 & 0.31 & 0.22 \\
\hline
\end{tabular}

Notes: Unit of analysis is a participant

Just over and just under one quarter of the students made equal allocations in the random and earned treatments respectively, while the proportions leaving the initial endowments untouched were zero and just over ten percent respectively. More than half of the employed made equal allocations in the random treatment, while less than a third did so in the earned treatment. The proportion leaving the initial endowments untouched moved in the opposite direction, from less than 5 and over 15 percent. Just over one third of the unemployed made equal allocations under both treatments (marginally more under the earned treatment). However, while none left the initial endowments untouched under the random treatment, just under 10 percent did so under the earned treatment.

Under both treatments all participant types allocated more to themselves as compared to others, with students allocating the most to themselves on average. The table suggests that employed and unemployed participants allocated somewhat less on average to themselves in the earned treatment. However, the difference is only statistically significant in the case of the employed. 
Figure 1

Allocations to others by treatment and decision-making subject type in Oxford

Random Treatment

Students

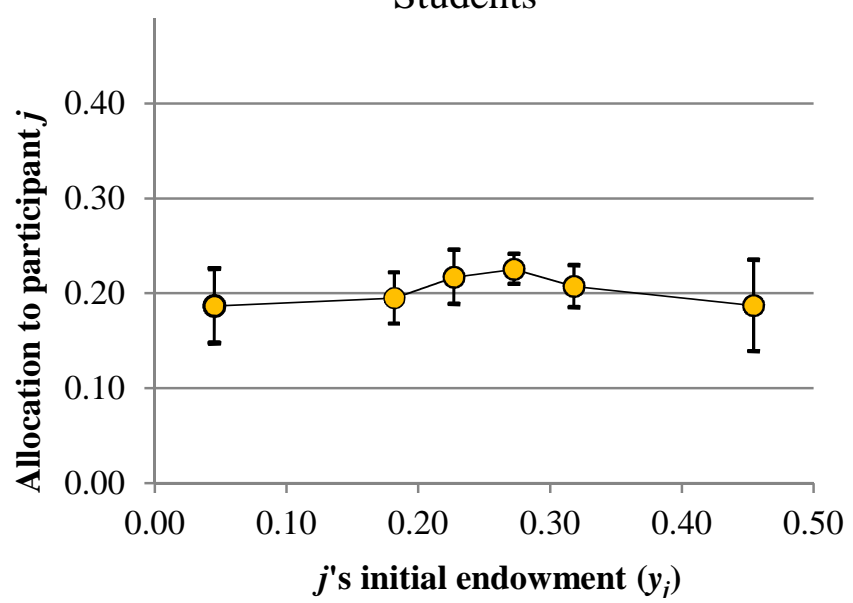

Employed

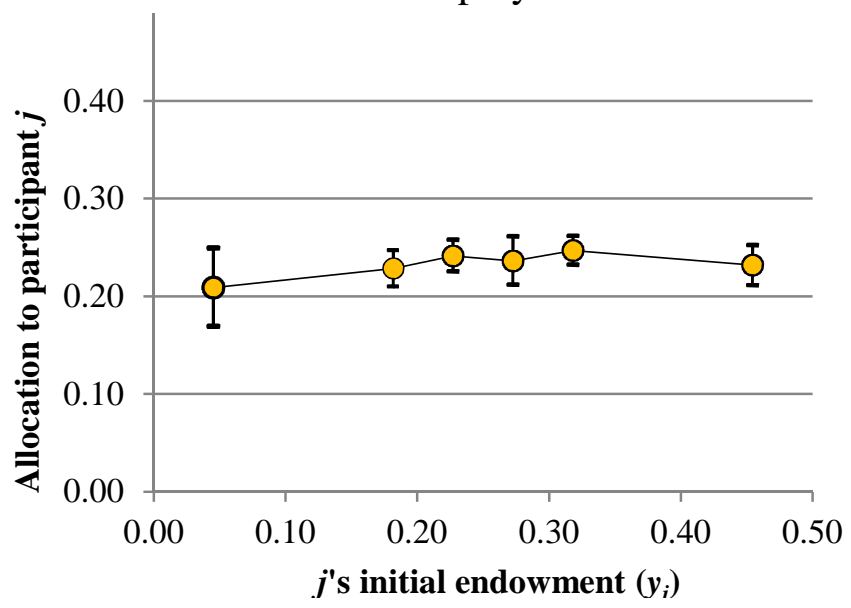

Unemployed

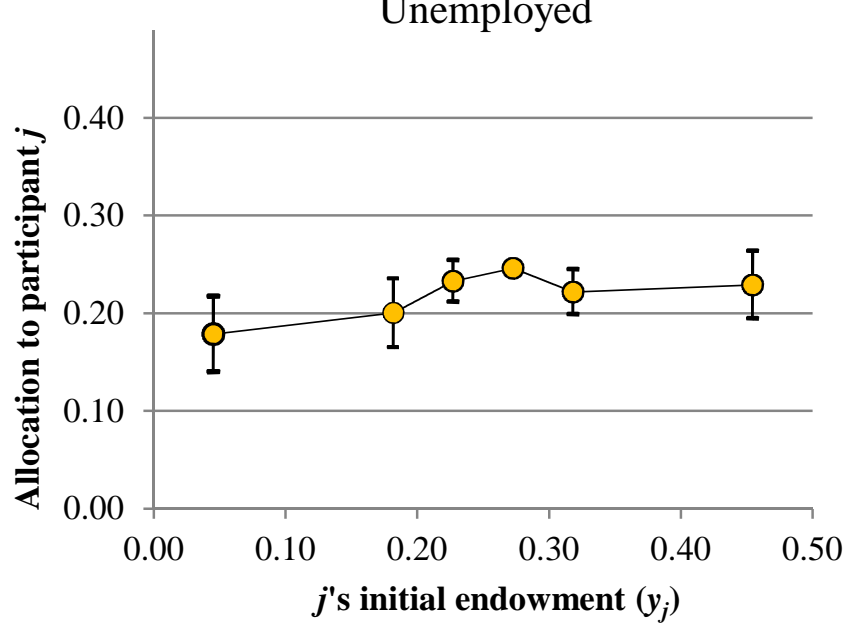

Earned Treatment

Students

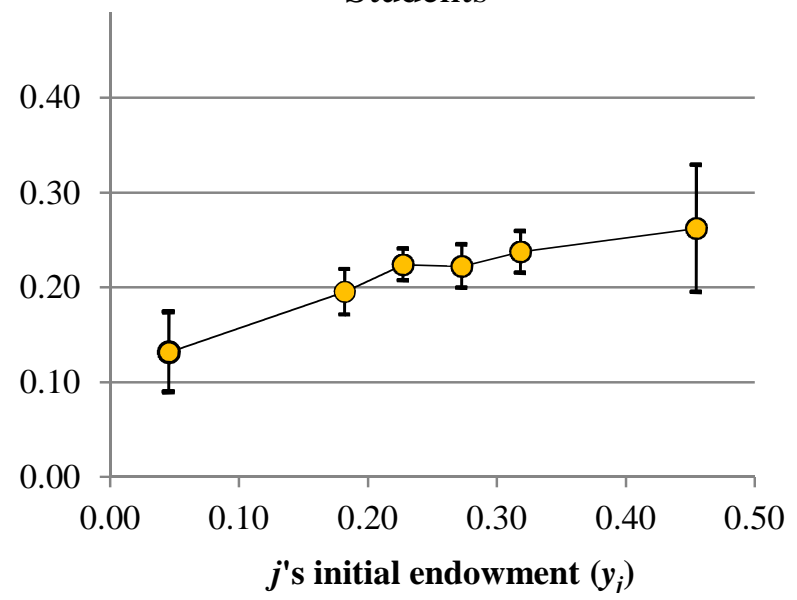

Employed

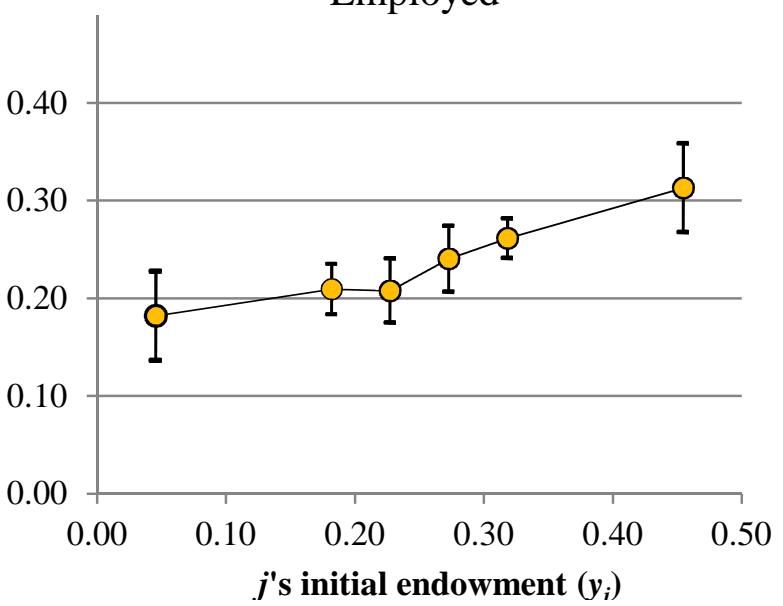

Unemployed

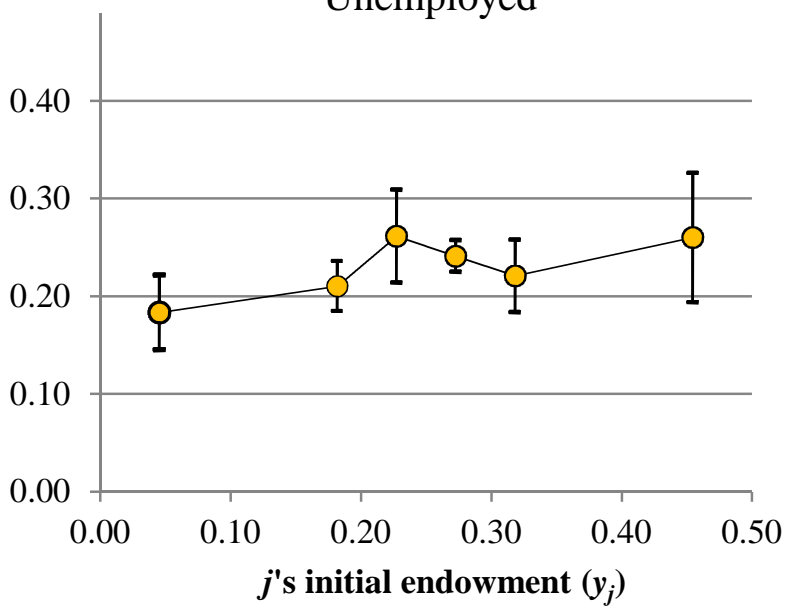

Notes: The circular points on these graphs indicate the mean allocations by $i$ to $j$, conditional on $j$ 's initial endowment, $y_{j}$. The vertical lines through the circular points indicate the $95 \%$ confidence intervals, corrected for interdependence within allocator, $i$. 
The differences in mean allocations to self and others are consistent with the theoretical model presented above. The proportions of participants choosing equal allocations and not to redistribute at all are broadly in line with our hypotheses. However, these proportions do not account for intermediate types. To incorporate them in the analysis we move to Figure 1, in which mean allocations to others are plotted against those others' initial endowments for each participant type under each treatment.

The upper and middle panels in Figure 1 show that students and the employed conditioned final allocations to others on those others' initial endowments in the earned treatment, but not in the random treatment. For both types of participant, the EEE manifests as an anticlockwise rotation about a midpoint. In contrast, the graphs for the unemployed (lower panel) reveal no such rotation. There appears to be a positive relationship between final allocations and initial endowments under both treatments, but there is no evidence of an EEE here. Figure 1 provides further but still preliminary support for our hypotheses.

In Table 3 we present a series of linear regressions conforming to either Model 1 or Model 2 above. The first, second, and third columns contain estimations of Model 1 for students, the employed, and the unemployed respectively. The estimations for students and the employed reveal the expected EEE: the coefficient $a_{1}$, on the earned treatment identifier, $E$, is negative and significant; the coefficient, $a_{3}$, on $j$ 's initial endowment, $y_{j}$, interacted with the earned treatment identifier, $E$, is positive and significant. Finally, the coefficient, $a_{2}$, on $j$ 's initial endowment, $y_{j}$, uninteracted is insignificant. Together, these results indicate that the rotations in the relationships between final allocations and initial endowments from flat in the random treatment to upward-sloping in the earned treatment that we observed in Figure 1 are statistically significant. In the earned treatment, a one percentage point increase in initial endowment leads to a 0.3 percentage point increase in final allocations made by students and a 0.27 percentage point increase in final allocations made by employed participants. 
The estimation for the unemployed tells a different story. Here the significant positive coefficient, $a_{2}$, on $j$ 's initial endowment, $y_{j}$, uninteracted indicates a positive relationship between those initial endowments and final allocations, while the small and insignificant coefficients $a_{1}$, on $E$, and $a_{3}$, on the interaction between $y_{j}$ and $E$, indicate no EEE. Finally, it is worth noting that the slope of the relationship between initial endowments and final allocations is considerably smaller in magnitude than the slope in the earned treatment for students and the employed. Here, a one percentage point increase in initial endowment leads to a 0.13 percentage point increase in final allocations.

\section{Table 3}

\section{Regression analysis of allocations to others in the UK}

Dependent variable $=$ participant $i$ 's final allocation to participant $\mathrm{j}$

\begin{tabular}{|c|c|c|c|c|}
\hline & Students & Employed & Unemployed & $\begin{array}{l}\text { Unemployed } \\
\text { compared with } \\
\text { Students and } \\
\text { Employed }\end{array}$ \\
\hline \multirow[t]{2}{*}{ Earned treatment $(\mathrm{E})$} & $-0.063^{* *}$ & $-0.066^{* *}$ & 0.001 & $-0.064^{* * *}$ \\
\hline & -0.027 & -0.029 & -0.026 & -0.02 \\
\hline \multirow[t]{2}{*}{ j's initial endowment $\left(\mathrm{y}_{\mathrm{j}}\right)$} & 0.021 & 0.064 & $0.129^{* *}$ & 0.037 \\
\hline & -0.035 & -0.047 & -0.053 & -0.029 \\
\hline \multirow[t]{2}{*}{$y_{j} \times E$} & $0.297^{* * *}$ & $0.273^{* * *}$ & 0.038 & $0.294^{* * *}$ \\
\hline & -0.098 & -0.103 & -0.097 & -0.071 \\
\hline \multirow[t]{2}{*}{ Unemployed } & & & & -0.023 \\
\hline & & & & -0.022 \\
\hline \multirow[t]{2}{*}{ Unemployed $x \mathrm{E}$} & & & & $0.064^{* *}$ \\
\hline & & & & -0.032 \\
\hline \multirow[t]{2}{*}{$\mathrm{y}_{\mathrm{j}} \times$ Unemployed } & & & & 0.092 \\
\hline & & & & -0.06 \\
\hline \multirow[t]{2}{*}{$\mathrm{y}_{\mathrm{j}} \mathrm{x}$ Unemployed $\mathrm{x}$} & & & & $-0.256^{* *}$ \\
\hline & & & & -0.119 \\
\hline \multirow[t]{2}{*}{ Constant } & $0.197^{\star * *}$ & $0.216^{* * *}$ & $0.182^{* * *}$ & $0.205^{\star * *}$ \\
\hline & -0.013 & -0.015 & -0.02 & -0.01 \\
\hline Observations & 219 & 168 & 174 & 561 \\
\hline
\end{tabular}


When we pool the student and employed samples and estimate an appropriately adjusted version of Model 2, we find no significant differences in behaviour between the two participant types. ${ }^{11}$ However, when we pool across all three participant types and estimate Model 2, distinguishing between the unemployed and the other two types, the coefficients and standard errors reported in the fourth column of Table 3 are returned.

The significant positive coefficient, $a_{5}$, on the interaction between the unemployed identifier and the earned treatment identifier, $E$, and the significant negative coefficient, $a_{7}$, on the three way interaction between the unemployed identifier, $U_{i}, y_{j}$ and $E$ indicate that the unemployed are significantly different in terms of the treatment effect. In addition, linear restriction tests do not allow us to reject the hypotheses that $a_{1}+a_{5}=0$ and $a_{3}+a_{7}=0$ indicating, once again, that the unemployed are not subject to an EEE. ${ }^{12}$

\subsection{Cape Town, South Africa}

We ran 15 experimental sessions in Cape Town using the same protocol we used in Oxford. At first glance, the participant sample for the Cape Town experiment appeared very similar to the Oxford sample; it included 101 students, 72 employed and 63 unemployed people. However, while setting up for the recruitment it became clear that our assumptions about how participant types map onto economic status would not apply as well in Cape Town as in Oxford. First, the majority (75 percent) of the unemployed in our Oxford sample were receiving means-tested government cash transfers at the time of the experiment indicating that they were indeed of relatively low economic status, while in Cape Town there were no equivalently indicative

\footnotetext{
${ }^{11}$ The estimations are not tabulated but are available from the authors on request.

${ }^{12}$ To investigate the robustness of the results presented in the far right-hand column of Table 3 , we introduce a series of control variables and their corresponding interactions with $y_{j}, E$ and $y_{j} \mathrm{x} E$ into the model. To minimise the problem of multicollinearity, we introduced each control plus its corresponding interaction terms one control at a time. The key results presented above are robust to the inclusion, following this protocol, of several experimental variables and $i$ 's age, sex and education. To control for differences in selfishness $\left(\beta_{i}\right)$, we re-estimated the models including allocator $(i)$ fixed effects. The results are similar, except that the unemployed are then found to exhibit a small, weakly significant EEE, driven by the unemployed who are relatively well of and, hence, not eligible for government transfers. See on-line Supplementary Information for details.
} 
government cash transfers. Second, owing to the existence of the government cash transfers in the UK, unemployment in the UK is clearly defined whereas in South Africa it is not. Given this ambiguity combined with there being no safety-net and unemployment being high (around 25 percent as compared with just under 8 percent in the UK at the end of 2010) we conjectured that there may be many Cape Town residents who work part time, casually or rarely and who variably refer to themselves as employed and unemployed. Third, in comparison to Brooks and Oxford University, the University of Cape Town, in partnership with various non-governmental organizations and the government, is far more actively seeking to include individuals from low income households among its enrolled students.

So, in Cape Town we asked the experimental participants to complete a more comprehensive post-experimental questionnaire designed to give us an alternative measure by which to distinguish between individuals of low and high economic status. The resulting data supported our conjectures about type and economic status being only weakly associated in Cape Town. Ten out of the 63 unemployed people reported positive monthly earnings, with the average across those ten being 960 Rand (142 USD) and the maximum being 2,000 Rand (approximately 300 USD). The latter is considerably lower than the average stated monthly earnings of the selfproclaimed employed people, which are approximately 6,000 Rand. However, 30 percent of the self-proclaimed employed stated that they earned less than 2,000 Rand. ${ }^{13}$

\footnotetext{
${ }^{13}$ This percentage should be viewed with caution as earnings are notoriously difficult to measure using surveys. The proportion of self-proclaimed unemployed reporting positive monthly earnings is less likely to be subject to measurement error. Our data is consistent with Fields (2000), who describes South Africa as having an "employment problem" rather than an unemployment problem and characterizes the problem as encompassing not only unemployment but also low hourly wages and low work hours.
} 


\section{Table 4}

Participants and treatment assignment in South Africa

\begin{tabular}{|c|c|c|c|c|}
\hline & \multicolumn{4}{|c|}{ Participant sample } \\
\hline & All & Students & Employed & Unemployed \\
\hline Sample sizes & 236 & 101 & 72 & 63 \\
\hline \multicolumn{5}{|l|}{ Characteristics } \\
\hline Female (\%) & $53 \%$ & $46 \%$ & $68 \%$ & $49 \%$ \\
\hline Age & 30.35 & 22.05 & 38.56 & 34.27 \\
\hline Years in education & 12.22 & 13.27 & 12.44 & 10.28 \\
\hline \multicolumn{5}{|l|}{ Economic status } \\
\hline Rich & $3 \%$ & $3 \%$ & $0 \%$ & $5 \%$ \\
\hline High income & $6 \%$ & $13 \%$ & $3 \%$ & $0 \%$ \\
\hline Middle income & $39 \%$ & $54 \%$ & $46 \%$ & $7 \%$ \\
\hline Low income & $33 \%$ & $22 \%$ & $36 \%$ & $47 \%$ \\
\hline Poor & $19 \%$ & $8 \%$ & $15 \%$ & $42 \%$ \\
\hline \multicolumn{5}{|l|}{ Treatments } \\
\hline Unearned & $39 \%$ & $33 \%$ & $42 \%$ & $46 \%$ \\
\hline Earned & $61 \%$ & $67 \%$ & $58 \%$ & $54 \%$ \\
\hline
\end{tabular}

In addition, a question inviting the participants to categorize their households as either rich, upper income, middle income, low income, or poor revealed that there was considerable overlap not only between the employed and unemployed, but also between the students and the other two groups. Table 4 shows that, while the unemployed in our sample were far more likely than the employed and the students to perceive their households as low income or poor, there was greater variation in perceptions among the employed and students. So, 87 percent of the unemployed indicated that they were from low income or poor households and 51 and 30 percent of the employed and the students respectively did likewise. Table 4 also shows that, as in Oxford, individual characteristics varied markedly across the students, employed and unemployed sub-samples. However, here the relative characteristics of the sample seem to correspond closely with data from large-scale surveys. Specifically, relative to the employed, the unemployed are younger and more likely to be male (Bhorat, 2005). ${ }^{14}$

${ }^{14}$ They are also more likely to be of African origin. 
In Table 5, we present a brief summary of behaviour for the South African participants that played under the random and earned treatments. In the first column, we pool across all participants. In the second, third, and fourth columns we present the same statistics for students, the employed, and the unemployed participants separately. Then, in the fifth and sixth columns we present the same statistics for high and low status participants. We define high status participants as those who reported that their households were rich or high or middle income and low status participants as those who reported that their households were poor or low income. ${ }^{15}$

Table 5

South African experimental data summarized

\begin{tabular}{|c|c|c|c|c|c|c|}
\hline & \multicolumn{6}{|c|}{ Participant sample } \\
\hline & All & Student & Employed & Unemployed & $\begin{array}{c}\text { High } \\
\text { economic } \\
\text { status }\end{array}$ & $\begin{array}{c}\text { Low } \\
\text { economic } \\
\text { status }\end{array}$ \\
\hline \multicolumn{7}{|l|}{ Random treatment } \\
\hline Allocated zero to all others (\%) & $1.1 \%$ & $3.0 \%$ & $0.0 \%$ & $0.0 \%$ & $2.3 \%$ & $0.0 \%$ \\
\hline Allocated $1 / 4$ to each $(\%)$ & $40.2 \%$ & $24.2 \%$ & $66.7 \%$ & $31.0 \%$ & $40.9 \%$ & $39.6 \%$ \\
\hline Left initial endowments unchanged (\%) & $3.3 \%$ & $0.0 \%$ & $0.0 \%$ & $10.3 \%$ & $0.0 \%$ & $6.3 \%$ \\
\hline Allocation to self (mean proportion) & 0.34 & 0.44 & 0.28 & 0.29 & 0.36 & 0.32 \\
\hline Allocation to others (mean proportion) & 0.22 & 0.19 & 0.24 & 0.24 & 0.21 & 0.23 \\
\hline \multicolumn{7}{|l|}{ Earned treatment } \\
\hline Allocated zero to all others (\%) & $3.5 \%$ & $5.9 \%$ & $2.4 \%$ & $0.0 \%$ & $4.4 \%$ & $2.7 \%$ \\
\hline Allocated $1 / 4$ to each $(\%)$ & $26.4 \%$ & $11.8 \%$ & $38.1 \%$ & $41.2 \%$ & $15.9 \%$ & $36.0 \%$ \\
\hline Left initial endowments unchanged (\%) & $9.7 \%$ & $11.8 \%$ & $9.5 \%$ & $5.9 \%$ & $13.0 \%$ & $6.7 \%$ \\
\hline Allocation to self (mean proportion) & 0.35 & 0.44 & 0.27 & 0.28 & 0.38 & 0.32 \\
\hline Allocation to others (mean proportion) & 0.22 & 0.19 & 0.24 & 0.24 & 0.21 & 0.23 \\
\hline
\end{tabular}

Notes: Unit of analysis is a participant

Table 5 reveals that only one and three percent of the participants in the random and earned treatments respectively acted in accordance with pure selfishness. These proportions are even smaller than those observed in Oxford. The table also reveals that 40 and 26 percent of the participants made equal allocations to themselves and others under the random and earned

\footnotetext{
15 This approach yields two similarly sized sub-samples and obviates the problem that individuals from high income and rich households tend to understate their economic status when asked this subjective question.
} 
treatments respectively and that, while only three percent left the initial endowments untouched in the random treatment, ten percent did so in the earned treatment.

Almost one quarter of the students made equal allocations in the random treatment, while only just over ten percent did likewise in the earned treatment. The proportion leaving the initial endowments untouched moved in the opposite direction, from zero to over ten percent. Two thirds of the employed made equal allocations in the random treatment, while less than forty percent did so in the earned treatment. Again, the proportion leaving the initial endowments untouched moved in the opposite direction, from zero to just under ten percent. As in Oxford, the unemployed were distinct. Just under one third made equal allocations under the random treatment, while over forty percent did so in the earned treatment. And the proportion leaving the initial endowments untouched moved in the opposite direction, from over ten percent in the random treatment to just over five percent in the earned treatment.

Dividing the sample according to economic status reveals that just over forty percent of the high status participants made equal allocations under the random treatment, while only just over fifteen percent did so in the earned treatment. Once again, the proportion leaving the initial endowments untouched moved in the opposite direction, from zero in the random treatment to almost fifteen percent in the earned treatment. In contrast, the low status participants were barely affected by treatment: in both, just under forty percent made equal allocations (marginally fewer in the earned treatment) and just over five percent left the initial endowments unaltered.

As in Oxford, under both treatments all participant types allocated more to themselves as compared to others, with students allocating most to themselves on average. Average allocations to self and others are almost indistinguishable across treatments. 
The differences in mean allocations to self and others are consistent with the theoretical model presented above. The proportions of participants choosing equal allocations and electing not to redistribute at all are broadly in line with our hypotheses. However, to incorporate intermediate types in the analysis we must move to Figures 2 and 3, in which mean allocations to others are plotted against those others' initial endowments for the various participant types under each treatment. In Figure 2 the sample is divided into students, the employed, and the unemployed. In Figure 3 the sample is divided into participants with high and low economic status.

The middle panel of Figure 2 reveals an EEE for the employed; they conditioned final allocations to others on those others' initial endowments in the earned treatment, but not in the random treatment. The upper and lower panels reveal no sign of an EEE for the students and the unemployed, although the lower panel suggests that the unemployed conditioned their final allocations to others on those others' initial endowments irrespective of treatment. In Figure 3 the upper panel very clearly reveals an EEE for the high economic status participants. In contrast, the lower panel reveals no evidence of an EEE for the low status individuals, but clearly indicates that they conditioned final allocations to others on those others' initial endowments in both the random and the earned treatments. 
Figure 2

Allocations to others by treatment and decision-making subject type in Cape Town

Random Treatment

Students

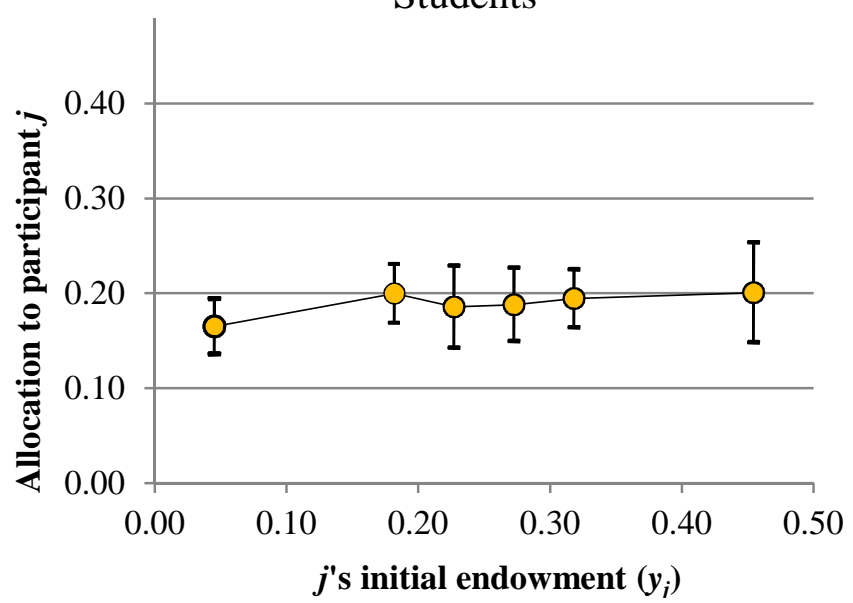

Employed

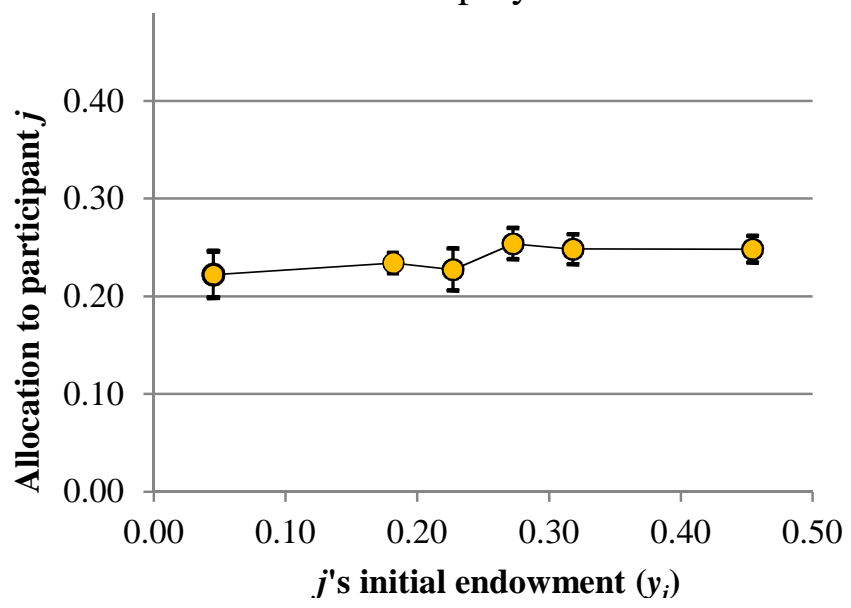

Unemployed

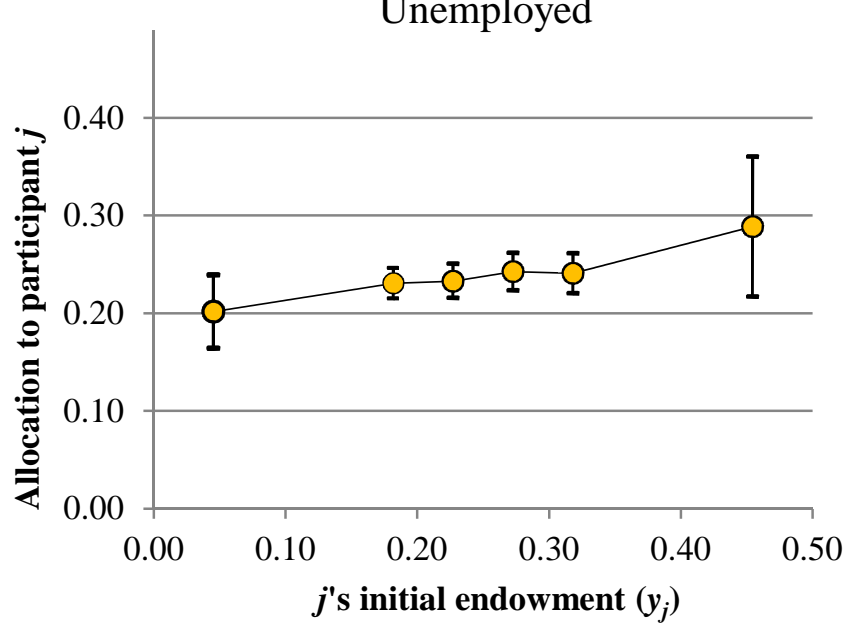

Earned Treatment

Students

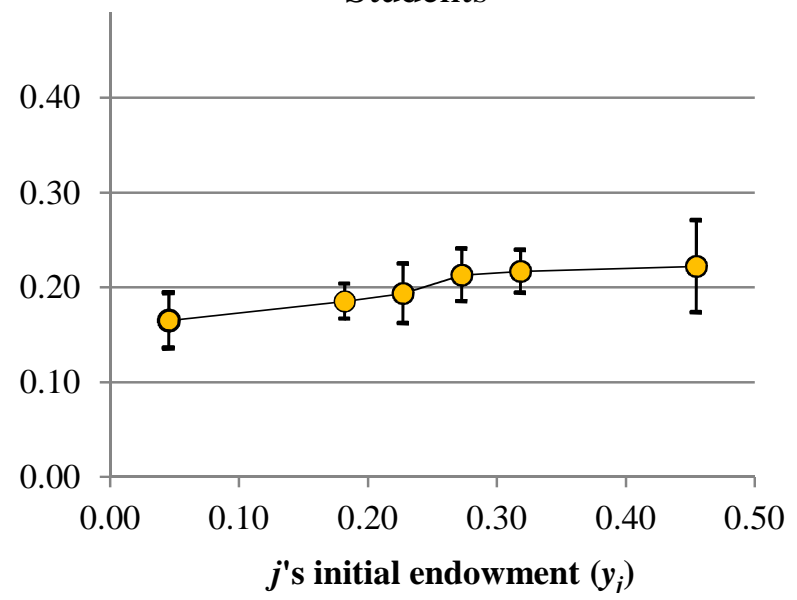

Employed

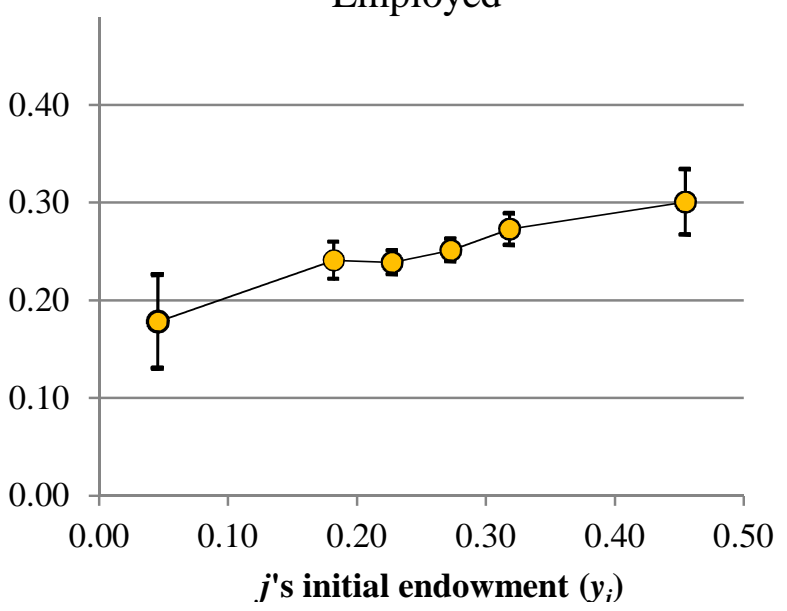

Unemployed

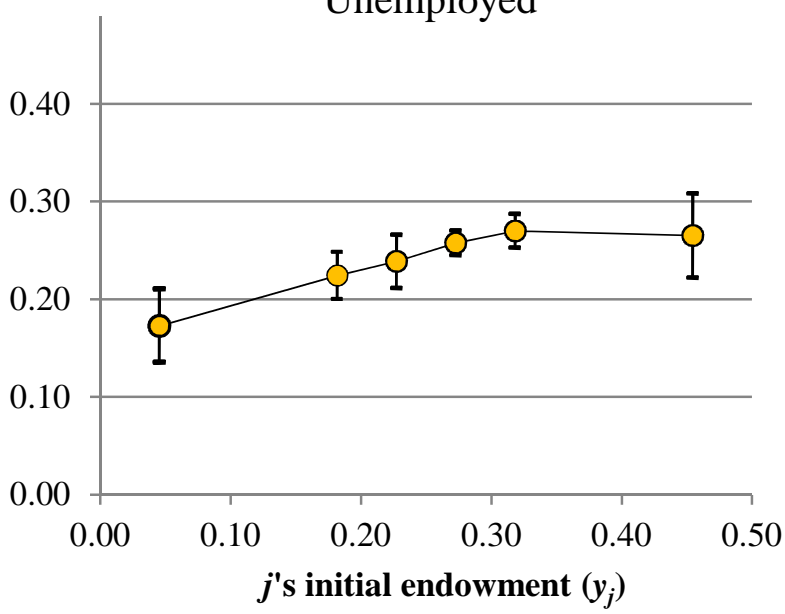

Notes: The circular points on these graphs indicate the mean allocations by $i$ to $j$, conditional on $j$ 's initial endowment, $y_{j}$. The vertical lines through the circular points indicate the $95 \%$ confidence intervals, corrected for interdependence within allocator, $i$. 
Figure 3

Allocations to others in Cape Town by treatment and decision-making subjects' economic status
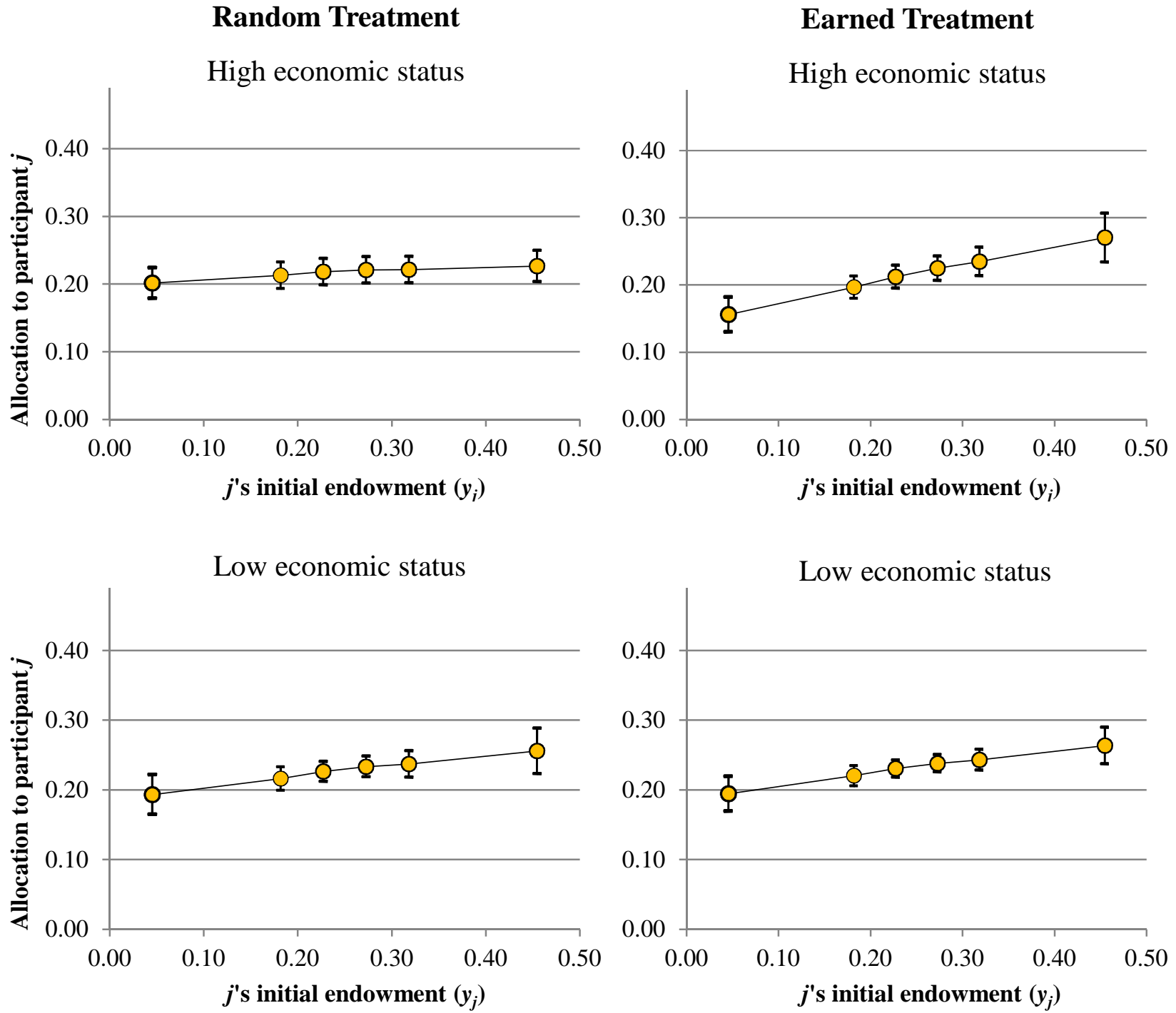

Notes: The circular points on these graphs indicate the mean allocations by $i$ to $j$, conditional on $j$ 's initial endowment, $y_{j}$. The vertical lines through the circular points indicate the $95 \%$ confidence intervals, corrected for interdependence within allocator, $i$. 
The regressions in the first three columns of Table 6 confirm that the employed were subject to an EEE, while the students and the unemployed were not. They also reveal that not only the unemployed but also, to a lesser extent, the employed conditioned final allocations to others on those others' initial endowments in the random treatment. The regressions in the fourth and fifth columns confirm that the high economic status participants were subject to an EEE, while the low economic status participants were not. They also reveal that low and, to a lesser degree, high economic status participants conditioned final allocations to others on those others' initial endowments in the random treatment.

\section{Table 6}

\section{Regression analysis of allocations to others in South Africa}

Dependent variable $=$ participant i's final allocation to participant $j$

Excluded from the samples: allocations made by participants who allocate zero to everyone other than themselves

\begin{tabular}{|c|c|c|c|c|c|c|}
\hline & Students & Employed & Unemployed & $\begin{array}{l}\text { High } \\
\text { economic } \\
\text { status }\end{array}$ & $\begin{array}{l}\text { Low } \\
\text { economic } \\
\text { status }\end{array}$ & $\begin{array}{l}\text { High and } \\
\text { low } \\
\text { economic } \\
\text { status } \\
\text { compared }\end{array}$ \\
\hline Earned treatment (E) & $\begin{array}{l}-0.015 \\
(0.026)\end{array}$ & $\begin{array}{l}-0.042^{*} \\
(0.022)\end{array}$ & $\begin{array}{l}-0.013 \\
(0.027)\end{array}$ & $\begin{array}{c}-0.056^{* * *} \\
(0.020)\end{array}$ & $\begin{array}{c}0.001 \\
(0.022)\end{array}$ & $\begin{array}{c}-0.056^{* * *} \\
(0.020)\end{array}$ \\
\hline j's initial endowment $\left(\mathrm{y}_{\mathrm{j}}\right)$ & $\begin{array}{c}0.065 \\
(0.049)\end{array}$ & $\begin{array}{c}0.075^{* * *} \\
(0.027)\end{array}$ & $\begin{array}{l}0.191^{* *} \\
(0.094)\end{array}$ & $\begin{array}{l}0.061^{*} \\
(0.032)\end{array}$ & $\begin{array}{l}0.153^{* *} \\
(0.064)\end{array}$ & $\begin{array}{l}0.061^{*} \\
(0.032)\end{array}$ \\
\hline$y_{j} \times E$ & $\begin{array}{c}0.095 \\
(0.089)\end{array}$ & $\begin{array}{l}0.210^{* *} \\
(0.082)\end{array}$ & $\begin{array}{c}0.054 \\
(0.110)\end{array}$ & $\begin{array}{l}0.218^{* * *} \\
(0.075)\end{array}$ & $\begin{array}{c}0.017 \\
(0.084)\end{array}$ & $\begin{array}{l}0.218^{* * *} \\
(0.075)\end{array}$ \\
\hline Low economic status $(\mathrm{L})$ & & & & & & $\begin{array}{l}-0.013 \\
(0.020)\end{array}$ \\
\hline$L \times E$ & & & & & & $\begin{array}{l}0.056^{*} \\
(0.030)\end{array}$ \\
\hline$y_{j} \times L$ & & & & & & $\begin{array}{c}0.091 \\
(0.072)\end{array}$ \\
\hline$y_{j} \times L \times E$ & & & & & & $\begin{array}{l}-0.201^{*} \\
(0.112)\end{array}$ \\
\hline Constant & $\begin{array}{c}0.175^{\star * *} \\
(0.019)\end{array}$ & $\begin{array}{l}0.221^{* * *} \\
(0.009)\end{array}$ & $\begin{array}{l}0.191^{* * *} \\
(0.022)\end{array}$ & $\begin{array}{l}0.202^{* * *} \\
(0.012)\end{array}$ & $\begin{array}{c}0.188^{* * *} \\
(0.017)\end{array}$ & $\begin{array}{c}0.202^{* * *} \\
(0.012)\end{array}$ \\
\hline Observations & 288 & 213 & 189 & 327 & 363 & 690 \\
\hline
\end{tabular}

Despite the apparent differences between the regressions in the first and second columns of

Table 6, when we pool the student and employed samples and estimate an appropriately adjusted 
version of Model 2, we find no significant difference in behaviour between the two types. Using a similar approach, we find no significant difference in behaviour between students and the unemployed, and the employed and the unemployed. However, when we work with the full sample and estimate an appropriately adjusted version of Model 2 that includes an identifier for the participants with low economic status and interacts this variable with $y_{j}, E$ and $y_{j} \times E$, the estimates presented in the sixth and final column of Table 6 are returned. These reveal that the differences in treatment effects between the high and low status participants are statistically significant. It seems that, in Cape Town, individual tendencies to acknowledge entitlement owing to effort and productivity are associated with participants' relative economic status rather than their current or anticipated labour market status. ${ }^{16}$

Before concluding, it is interesting to note that when the model presented in the sixth and final column of Table 6 is estimated using only the student sub-sample, similar results are returned. The students from middle and higher income households exhibit an EEE, while the students from lower income and poor households do not. Finally, additional analysis of the Oxford data revealed that we could marginally improve on our earlier results by accounting for differences in economic status within the student and unemployed participant samples. Further, while there were many reasons why we should not expect the Oxford and Cape Town data to pool, when doing so we found no evidence of a difference in the relationship between individual notions of distributive justice and relative economic status. This null finding supports the conclusion that it is relative economic status within a society that is associated with an individual's notions of

\footnotetext{
${ }^{16} \mathrm{We}$ introduced a series of control variables and their corresponding interactions with $y_{j}, E$ and $y_{j} \mathrm{x} E$ into the model in the final column of Table 6 , one control variable at a time. The key results presented above are robust to the inclusion, following this protocol, of several experimental variables and $i$ 's ethnicity and age. When the sex and education of $i$ are controlled for in this way some results are lost. However, in both cases it can be shown that this is owing to multicollinearity relating to multiple interaction terms with common elements and that the interactions involving the controls have no significant explanatory power. The findings are robust to the inclusion of allocator fixed effects in the models. See on-line Supplementary Materials for details.
} 
distributive justice and that this is a generalizable result even though definitions of relative economic status may vary across societies. ${ }^{17}$

\section{SUMMARY, DISCUSSION AND CONCLUSION}

This paper presented the findings from a series of experiments designed to investigate whether individuals' tendencies to acknowledge entitlement owing to effort and productivity are associated with their economic status relative to others within their societies. Specifically, the experiments allowed us to establish whether the earned endowment effect (EEE) varied with the relative (within society) economic status of the experimental participants. We hypothesised that, while the EEE would be significant among high economic status individuals, i.e, that high economic status individuals would make allocations to others that reflect those others' initial endowments considerably more when those endowments were earned rather than pure windfall gains, among low status individuals the EEE would be less pronounced or absent.

The findings supported this hypothesis. In the UK, among students and the employed there was a statistically significant EEE, among the unemployed there was not and the difference between the two participant pools was significant. And in South Africa, among individuals who classified their own households as rich or high or middle income there was a statistically significant EEE, among individuals who classified their own households as poor or low income there was not and the difference between the two participant pools was significant.

The objective of this paper is to take a first step towards reconciling three literatures, i.e.: the experimental studies focusing on US and European students who have repeatedly acknowledged earned entitlement; the studies of Jakiela (2011), Cappelen et al (2013) identifying Africa-based

\footnotetext{
${ }^{17}$ The two results reported in this paragraph are based on analyses reported in the online Supplementary Information.
} 
subject pools that are less or entirely disinclined to acknowledge earned entitlement; the surveybased analyses of Alesina and Giuliano (2011) and others, indicating that people at the lower end of the income distributions of developed countries might also be less or entirely disinclined to acknowledge earned entitlement; and the study by Jakiela et al (2014) revealing a causal effect of academic achievement on acknowledgement of earned entitlement within an African country.

That US and European students have been found, repeatedly, to acknowledge earned entitlement is consistent with our findings. Like Cappelen et al (2013) we found a difference between European and African students. However, by distinguishing between students from relatively well off and poorer households we were able to reconcile this finding with the general model. This finding is not consistent with the findings of Jakiela et al (2014). However, the inconsistency may be owing to differences in experimental design. All of our findings are consistent with the survey-based analyses of Alesina and Giuliano (2011) and others and indicate that differences in attitudes to redistribution between rich and poor are, at least in part, owing to differences in notions of distributive justice. Jakiela's (2011) Kenyan farmers are distinct from all of our experimental participants. Their tendency not to acknowledge earned entitlement could be owing to their low economic status relative to other Kenyans and, therefore, could be consistent with our findings. However, further work would be required to establish that this is the case.

One of our findings was unexpected. For the low status participants in Cape Town and the unemployed in Oxford the absence of an EEE was, in part, owing to such participants conditioning their allocations to others on those others' initial endowments even when those endowments were windfalls rather than earnings. This is consistent with the lower status individuals being less willing to take from others under any conditions. One possible explanation for this finding is that the laboratory context caused lower status participants to 
become more passive. However, Table 2 reveals that in Oxford the unemployed were the least likely to leave the initial endowment unchanged and Table 5 shows that, while the low status participants in Cape Town were more inclined than the high status participants to leave the initial endowments unchanged in the earned treatment, in the random treatment they were less inclined to do so. Another possible explanation is that, lower status individuals may have been less attentive to the task and so stopped reallocating before reaching their otherwise preferred distribution. If this were the case, we would expect this lack of attention to manifest also as lower productivity in the real effort task. However, in Oxford, it was the employed rather than the unemployed who were least productive and, in Cape Town, the relatively low status participants were only marginally less productive. ${ }^{18}$ Looking beyond the bounds of the experiment, there is one striking similarity between the low status participants in the Cape Town sample and the unemployed in the Oxford sample; on average they had 11.2 and 11.5 years of education respectively compared to 13.3 years of education for the rest of the participants. Perhaps the education systems in both countries are devised to ensure that those who leave education prior to or having just taken their first public exams are inculcated into believing that taking anything from other people is bad, while those who continue in education beyond this point are encouraged to think more freely. This would be worthy of further investigation.

Finally, there are certain aspects of our study that could be improved upon in future work. First and most importantly, our participant samples are not representative of the national populations from which they were drawn. In particular, in both the UK and South Africa our samples were entirely urban. Second, our survey data covered only a few variables of interest and did not go into as much depth concerning income and wealth as would have been ideal. Both of these concerns could be addressed by embedding the experiment within existing household or individual surveys covering random samples of respondents. Third, we conducted our

\footnotetext{
${ }^{18}$ See on-line Supplementary Information for details.
} 
experiment in only two societies. Ideally, one would conduct it in a larger number of societies that vary along different dimensions of interest. In particular, it would be interesting to replicate the experiment in one or more low income countries. Fourth, it is important to bear in mind that we have not identified a causal relationship. And finally, our findings tell us nothing about the preferences of the very rich.

Acknowledgements: We owe a considerable debt of thanks to Simon Headford, our script reader and long suffering recruiter of the unemployed participants in the UK experiment. We are also grateful to our research assistants and experimental participants. The research was funded by The John Fell Fund, University of Oxford, grant 092/235. Neither the John Fell Fund nor any of the authors' employers has a financial interest in the topic of the paper. Luis Miller acknowledges the financial support received from the Spanish Ministry of Economy and Competitiveness (grant ECO2012-30626) and the Basque Government (research group IT-78313).

\section{REFERENCES}

Alesina, A., Giuliano, P., 2011. Preferences for Redistribution. In: Benhabib, J., Bisin, A., Jackson, M. (Eds.), Handbook of Social Economics, North Holland Press.

Arden, F., Leibbrandt, M., Levinsohn. J., 2014. Income mobility in a high-inequality society: Evidence from the first two waves of the National Income Dynamics Study. Development Southern Africa 31(1), 16-30.

Babcock, L., Loewenstein, G., 1997. Explaining bargaining impasse: the role of self-serving biases. Journal of Economic Perspectives 11, 109-126.

Bardsley, N., 2008. Dictator game giving: Altruism or artefact? Experimental Economics 11, $122-133$ 
Bhorat, H., 2005. Poverty, Inequality and Labour Markets in Africa: A Descriptive Overview. Working Papers 05092, University of Cape Town, Development Policy Research Unit. Cappelen, A. W., Hole, A. D., Sorensen, E. O., Tungodden, B., 2007 The pluralism of fairness ideals: An experimental approach. American Economic Review 97 (3), 818-827.

Cappelen, A. W., Moene, K. O., Sorensen, E. O., Tungodden, B., 2013. Needs vs Entitlements An International Fairness Experiment. Journal of the European Economic Association 11, 574598.

Cherry, T. L., 2001. Mental Accounting and Other-regarding Behavior: Evidence from the Lab. Journal of Economic Psychology 22 (5), 605-615.

Cherry, T. L., Frykblom, P., Shogren, J. F., 2002. Hardnose the Dictator. American Economic Review, 92 (4), 1218-1221.

Drazen, A., 2002. Political Economy in Macroeconomics, Princeton University Press, Princeton. Fields, G. S., 2000. The Employment Problem in South Africa. Trade and Industry Monitor 16. Frohlich, N., Oppenheimer, J., Kurki, A., 2004. Modeling other-regarding preferences and an experimental test. Public Choice 119, 91-117.

Gantner, A., Güth, W., Königstein, M., 2001. Equitable choices in bargaining games with joint production. Journal of Economic Behavior and Organization 46, 209-225.

Hoffman, E., McCabe, K. A., Shachat, K., Smith, V. L., 1994. Preferences, Property Rights, and Anonymity in Bargaining Games. Games and Economic Behavior 7 (3), 346-380.

Jakiela, P., 2011. Social Preferences and Fairness Norms as Informal Institutions: Experimental Evidence. American Economic Review. Papers and Proceedings 101 (3), 509-513.

Jakiela, P., Miguel, E., te Velde, V., 2014. You've earned it: estimating the impact of human capital on social preferences. Experimental Economics.

Konow, J., 2001. Fair shares: Accountability and cognitive dissonance in allocation decisions. American Economic Review 90 (4), 1072-1091. 
List, J., 2007. On the Interpretation of Giving in Dictator Games. Journal of Political Economy 115(3), 482-493.

List, J., Cherry, T. L., 2008. Examining the Role of Fairness in High Stakes Allocation

Decisions. Journal of Economic Behavior and Organization 65, 1-8.

Miller, D., 1976. Social Justice, Clarendon Press, Oxford.

Milne, H., 1986., Desert, effort and equality. Journal of Applied Philosophy 3, 235-243.

Oxoby, R., Spraggon, J., 2008. Mine and yours: Property rights in dictator games. Journal of Economic Behavior and Organization 65, 703-713.

Personn, T., Tabellini, G., 2002. Political Economics: Explaining Economics Policy, MIT Press, Cambridge.

Platteau, J., 2000. Institutions, Social Norms and Economic Development. Harwood Academic Publishers, Amsterdam.

Ruffle, B. J., 1998. More is better, but fair is fair: Tipping in dictator and ultimatum games. Games and Economic Behavior 23 (2), 247-265.

Rutström, E., Williams, M. B., 2000. Entitlements and fairness: an experimental study of distributive preferences. Journal of Economic Behavior and Organization 43(1), 75-89. 